\title{
Juicy fruit and creepy crawlies: An electrophysiological study of the implicit Go/NoGo association task
}

Citation for published version (APA):

Banfield, J. F., van der Lugt, A. H., \& Münte, T. F. (2006). Juicy fruit and creepy crawlies: An electrophysiological study of the implicit Go/NoGo association task. Neuroimage, 31, 1841-1849. https://doi.org/10.1016/j.neuroimage.2006.02.017

Document status and date:

Published: 01/01/2006

DOI:

10.1016/j.neuroimage.2006.02.017

Document Version:

Publisher's PDF, also known as Version of record

Document license:

Taverne

Please check the document version of this publication:

- A submitted manuscript is the version of the article upon submission and before peer-review. There can be important differences between the submitted version and the official published version of record.

People interested in the research are advised to contact the author for the final version of the publication, or visit the DOI to the publisher's website.

- The final author version and the galley proof are versions of the publication after peer review.

- The final published version features the final layout of the paper including the volume, issue and page numbers.

Link to publication

\footnotetext{
General rights rights.

- You may freely distribute the URL identifying the publication in the public portal. please follow below link for the End User Agreement:

www.umlib.nl/taverne-license

Take down policy

If you believe that this document breaches copyright please contact us at:

repository@maastrichtuniversity.nl

providing details and we will investigate your claim.
}

Copyright and moral rights for the publications made accessible in the public portal are retained by the authors and/or other copyright owners and it is a condition of accessing publications that users recognise and abide by the legal requirements associated with these

- Users may download and print one copy of any publication from the public portal for the purpose of private study or research.

- You may not further distribute the material or use it for any profit-making activity or commercial gain

If the publication is distributed under the terms of Article $25 \mathrm{fa}$ of the Dutch Copyright Act, indicated by the "Taverne" license above, 


\title{
Juicy fruit and creepy crawlies: An electrophysiological study of the implicit Go/NoGo association task
}

\author{
Jane F. Banfield, * Arie H. van der Lugt, and Thomas F. Münte \\ Department of Neuropsychology, Otto von Guericke University, 2 (Pfaelzer Platz, Geb. 24), PO Box 4120, 39106 Magdeburg, Germany
}

Received 6 April 2005; revised 5 February 2006; accepted 13 February 2006

Available online 3 April 2006

\begin{abstract}
The Go/NoGo association task (GNAT) has been used in behavioral studies to measure the strength of association between different category groups and two poles of an evaluative dimension. However, reaction time data do not provide information about the neural time course of such associative information. We investigated event-related brain potentials (ERPs) elicited when participants were required to respond (Go) or withhold a response (NoGo) according to task instructions. Task instructions paired words from one of two taxonomic categories (fruit/bugs) with either pole of an evaluative dimension $(\mathrm{good} / \mathrm{bad})$. Within a given run, Go responses were assigned to one of the categories and one evaluative dimension. ERPs showed an increased negativity over frontal sites to NoGo as compared to Go responses. Moreover, NoGo minus Go difference waves showed that the N200 effect was delayed in trials within incongruent blocks (e.g., "Press if a bug word or a good word") as compared to trials within congruent blocks (e.g., "Press if a bug word or a bad word"). These results suggest that such associative attitude information is available at a very early stage of processing, less than $250 \mathrm{~ms}$ after seeing a fruit or a bug word. This finding is further discussed with respect to alternative explanations of the behavioral effect.

(c) 2006 Elsevier Inc. All rights reserved.
\end{abstract}

Keywords: Implicit; Association; Cognition; Attitudes; ERP; N200

We all have strong automatic attitudes towards certain objects and even categories of people. For example, most of us recoil when we see maggots, cockroaches, or decaying food but hold positive associations for plants and flowers or tasty food and drink. While there is a wealth of behavioral research concerning different aspects of evaluative processing (e.g., Bargh et al., 1996; Lakin and Chartrand, 2003; Fazio and Olson, 2003; Fazio et al., 1995; Kawakami et al., 2003; Stapel and Blanton, 2004), there is relatively little work addressing the neural time course of attitude activation. An event-related brain potential (ERP) study is ideally

\footnotetext{
* Corresponding author.

E-mail address: jane.banfield@nat.uni-magdeburg.de (J.F. Banfield).

Available online on ScienceDirect (www.sciencedirect.com).
}

suited to such an investigation. Not only can ERPs provide detailed information about the time course of the neural processing of an event, they can also indicate brain activity for both overt and absent responses (for example, where a response must be withheld; see Münte et al., 2000).

Implicit attitudes have been measured in a number of ways, including the Implicit Association Test (IAT). This test was designed to measure the strength of association ${ }^{1}$ between different categories and an evaluative dimension (Greenwald et al., 1998). In this dual-response test, reaction times (RTs) to stimuli should be faster when responses to a category and an associated evaluation are mapped to the same response key than when less associated items are mapped to the same response key. The IAT should be sensitive to automatic associations underlying implicit attitudes which cannot be tapped using more traditional self-report measures (Greenwald et al., 2002).

More recently, the Go/NoGo association task (GNAT) has been developed to examine the strength of association between two target categories (or a single target category) and two poles of an evaluative dimension, this time using a single-handed response (Nosek and Banaji, 2001). As in the IAT, the participant is required to simultaneously identify stimuli that belong to the target category and one pole of the evaluative dimension, and this pairing can be evaluatively consistent (e.g., make a response to fruit or to good words) or inconsistent (e.g., make a response to bug or to good words). Again, the test was designed to measure the strength of association between the evaluative component and the category. If, for example, individuals have a strong negative automatic evaluation of bugs, then their response latencies should reflect this, i.e., they should be able to respond more quickly to target words belonging to the insect category when the instructions pair insect words with bad words than when they pair insect words with good words. The idea is that it is easier to map a category and an evaluation onto the same single-handed response if they are congruent, that is, previously linked in memory.

\footnotetext{
${ }^{1}$ Strength of association can be seen in this context as the potential of one concept to activate another (Greenwald et al., 2002; see also Hebb, 1949).
} 
Behavioral studies using the IAT and the GNAT suggest that the implicit associations that we hold influence the way in which the category information is attended to or encoded, resulting in slower response latencies for incongruent pairings between a target category and an evaluative dimension (Greenwald et al., 1998; Nosek and Banaji, 2001). These RTs, however, do not reflect when such information becomes available, but rather mark the endpoint of processing (usually differences in RT means occur at approximately $650 \mathrm{~ms}$ ). The time-point at which this type of associative information becomes available during the processing of a stimulus remains unclear.

It should be mentioned at this point that there is a large body of work, from both behavioral and neuropsychological perspectives, that has investigated the time course of different aspects of evaluative processing. Much of this work suggests that basic evaluative reactions, for example, simply categorizing something as positive or negative, or approaching/avoiding a stimulus, involve minimal effort or processing, are extremely rapid and even automatic (for example, see Chen and Bargh, 1999; Fazio et al., 1986; Osgood, 1953; Zajonc, 1980, 1984, 2001), leading Duckworth et al. (2002) to conclude, "Evaluative responding can be immediate, unintentional, implicit (i.e. occurring without awareness), stimulus based, and linked directly to approach and avoidance behavioral tendencies" (p. 513). Moreover, these responses can exert a negative affect on the evaluation of other aspects of the environment or influence the way in which events are processed or attended to (e.g., Murphy and Zajonc, 1993).

The idea that we can rapidly and automatically classify stimuli in this basic fashion has gained support from brain imaging and electrophysiological studies, particularly with regard to fear in response to dangerous or anxiety-inducing stimuli (for example, see Carretié et al., 2005; LeDoux, 1998). Indeed, some stimuli can be evaluated rapidly and automatically, via subcortical structures such as the amygdala and even without the involvement of the cerebral cortex (LeDoux, 1998). Later, ventromedial prefrontal cortex (VMPFC) involvement in the processing of dangerous stimuli (such as fearful versus neutral faces) is thought to occur as early as 100-150 ms (e.g., Kawasaki et al., 2001; Holmes et al., 2003; Carretié et al., 2005), via input from subcortical structures such as the amygdala as well as areas of visual cortex (see Bar, 2003; Vuilleumier, 2002). Other work, comparing responses to the presentation of threatening, neutral, and friendly faces, has found early posterior negativity (EPN) to be the first cortical response reflecting the enhanced processing of emotional stimuli (emerging at approximately $200 \mathrm{~ms}$ and peaking between 240 and $280 \mathrm{~ms}$ post-stimulus onset (Schupp et al., 2004).

In the present study, our aim was not to study immediate responses to fear or threat but rather to investigate a different aspect of information processing. Particularly, we were interested in investigating the type of associations measured by the GNAT. When does associative information, such as that held between a target category (e.g., fruit or bugs) and an attribute dimension (in this case, two poles of an evaluative dimension: good/bad) become available and when is it reflected in neural activity? In other words, when does this information influence decision making in an experimental setting? As mentioned earlier, an ERP study, using multi-channel recordings of event-related brain activity to provide a continuous window for examining effects, is ideally suited to such an investigation. While behavioral paradigms are only able to measure RTs associated with Go responses, an ERP study enables us to investigate the neural components underlying both Go and
NoGo responses, in trials within both congruent and incongruent blocks.

How is it possible to determine when such information becomes available in order for subjects to decide whether to respond or to withhold a response? Of central relevance is the N200, the socalled "NoGo component". A number of electrophysiological studies have shown that the stimulus-locked ERP in NoGo trials compared to that in Go trials is characterized by a negativity of about $1-4 \mu \mathrm{V}$ in size occurring with task-dependent onset latencies over the frontocentral scalp (Gemba and Sasaki, 1989; Kok, 1986; Pfefferbaum et al., 1985; Sasaki et al., 1993; Simson et al., 1977). Several lines of evidence link this frontal "N200" NoGo component to inhibitory processes. For example, invasive studies in behaving monkeys have revealed activity related to response inhibition in the prefrontal cortex in a Go/NoGo paradigm that gives rise to an N200 in humans (Sasaki et al., 1989). Sasaki et al. found that they could suppress the overt response on go trials by electrically stimulating the prefrontal cortex at the time that an N200 would normally have developed on a NoGo trial. Sasaki and Gemba (1993) presented a convincing case for an "inhibition" account of the N200 by comparing data from humans and monkeys. Moreover, destruction of prefrontal cortex in animals has been found to lead to a profound disturbance of performance in delayed response tasks (Fuster, 1989) and to an enhancement of disinhibition and impulsive behavior (Luria, 1973). Finally, brain imaging (fMRI) showed that individuals with greater orbitofrontal activation (contrast: NoGo versus Go) committed fewer false alarms, consistent with greater response inhibition (Casey et al., 1997). A cortical inhibitory network including the dorsolateral and inferior frontal lobe has been suggested by Konishi et al. (1999), Garavan et al. (1999) and Menon et al. (2001), among others.

Thus, it is likely that the N200 elicited by NoGo trials is related to inhibition processes in the prefrontal cortex. The presence of an N200 implies that information which can be used to determine whether or not a response is to be given must have been analyzed. The timing of the N200 is therefore seen to provide critical information about the timing of the availability of the information that is used to determine the Go/NoGo decision. Thorpe et al. (1996) have used the N200 effect to examine the time course of the visual processing of pictures. Specifically, subjects were asked to view complex visual scenes and to make a motor response whenever there was an animal in the scene and to withhold a response when no animal was present. They found an N200 for NoGo trials, which had a maximum at around $150 \mathrm{~ms}$ after picture onset. The peak latency of the N200 effect can be interpreted as the moment in time when sufficient visual information is available for a person to decide whether or not to respond, while the onset latency, that is the moment in time when Go and NoGo trial ERPs first diverge from each other at the scalp, can be taken as the time by which information becomes available to help the person decide whether or not to respond. The N200 effect has been used lately to investigate the availability of different types of linguistic information (semantic, syntactic, phonological) during language production (Jansma et al., 2004; Schmitt et al., 2000, 2001; Rahman et al., 2003; Rodriguez-Fornells et al., 2002).

In a design similar to that of the current study, RodriguezFornells et al. (2005) investigated cross-language interference in bilingual subjects in a $\mathrm{Go} / \mathrm{NoG}$ picture naming task. In addition to the N200 Go/NoGo effect, an increased negativity was observed in bilingual but not monolingual subjects in the trials where the responses given in the two different languages would have been 
different. Increased negativity in the conflicting Go responses appeared in the same latency range as the N200 NoGo component, and the authors argued that this increased negativity reflected a partial inhibition of the Go response in the active language by the interfering NoGo response that would be required for the nontarget language word. In a similar fashion, the inhibition of category congruent responses in the GNAT most likely requires additional processing. For example, "Press if insect or if good" means that the subject must respond to category incongruent stimuli (good words) and inhibit category congruent stimuli (bad words); in other words, the subject must inhibit their initial and automatic evaluation in order to complete the task accurately.

We therefore predicted that congruent Go responses should be faster than incongruent Go responses. For the ERPs, we expected N200 type signatures of inhibition, especially for the NoGo trials. Moreover, the N200 component should be later in incongruent NoGo trials as compared with congruent NoGo trials, reflecting conflicting information from prior associations held regarding the category items (fruit or bugs). Finally, we also expected an early negativity in incongruent Go responses, possibly reflecting partial inhibition of the response, consistent with the previous studies, as described above.

\section{Methods}

All materials were cleared by the institutional review board of the University of Magdeburg, Germany.

\section{Subjects}

Fifteen students at the University of Magdeburg (13 women, mean age 23.4) participated in the ERP experiment. All subjects were right-handed, healthy, and native German speakers. Four subjects were not included in the ERP analyses, due to either excessive artifacts or technical problems.

\section{Materials}

Please refer to Appendix A for a full list of the stimuli used. All words were matched for length and frequency (Baayen et al., 1993) and piloted for valence (only words strongly associated with the category were used (see Table 1)). The fruit and bugs categories comprised 25 nouns each, and the good and bad categories comprised similar proportions of nouns (13 for good, 14 for bad) and adjectives (12 for good, 11 for bad).

Table 1

Frequency (occurrences per 6 million tokens), length, and valence scores for words used in GNAT

\begin{tabular}{|c|c|c|c|c|}
\hline & Fruit & Bugs & Good & $\mathrm{Bad}$ \\
\hline \multirow[t]{3}{*}{ Mean frequency } & 13.32 & 13.72 & 16.32 & 15.8 \\
\hline & $\operatorname{Min}=0$ & $\operatorname{Min}=0$ & $\operatorname{Min}=0$ & $\operatorname{Min}=0$ \\
\hline & $\operatorname{Max}=74$ & $\operatorname{Max}=87$ & $\operatorname{Max}=72$ & $\operatorname{Max}=86$ \\
\hline \multirow[t]{3}{*}{ Mean length } & 7.64 & 6.64 & 9.32 & 8.72 \\
\hline & $\operatorname{Min}=4$ & $\operatorname{Min}=4$ & $\operatorname{Min}=3$ & $\operatorname{Min}=4$ \\
\hline & $\operatorname{Max}=14$ & $\operatorname{Max}=13$ & $\operatorname{Max}=15$ & $\operatorname{Max}=12$ \\
\hline \multirow[t]{3}{*}{ Mean pilot score } & 2.26 & 3.29 & 1.68 & 4.30 \\
\hline & $\operatorname{Min}=1.6$ & $\operatorname{Min}=2.4$ & $\operatorname{Min}=1$ & $\operatorname{Min}=3.2$ \\
\hline & $\operatorname{Max}=2.6$ & $\operatorname{Max}=4$ & $\operatorname{Max}=2.8$ & $\operatorname{Max}=5$ \\
\hline
\end{tabular}

\section{Procedure}

Subjects were seated $80 \mathrm{~cm}$ from a video-screen. Word stimuli were presented in black (arial font, $16 \mathrm{pt}$ ) on a white background. Each of eight blocks lasted approximately $8 \mathrm{~min}$ and comprised 100 trials, with an additional 20 practice trials presented at the beginning. The 100 word stimuli, randomly presented, comprised 25 fruit words, 25 bug words, 25 good words, and 25 bad words (see Appendix A). The order of blocks was rotated and counterbalanced across subjects. Trials lasted between 2500 and $3500 \mathrm{~ms}$. At the start of each trial, a fixation cross was presented for a random duration between 500 and $1500 \mathrm{~ms}$, immediately followed by a word which remained on the screen for $1500 \mathrm{~ms}$, followed again by fixation for $500 \mathrm{~ms}$. In each trial, the subject was required to either make a response (Go), or withhold a response (NoGo), depending on the instructions given at the start of the block, and presented again as a reminder at the end of the practice trials. There were four block types which determined which stimuli the subjects should respond to (Go) and which stimuli the subject should withhold a response to (NoGo). In two of the block types, instructions required subjects to respond only to a combination of words that was congruent in terms of prior associations:

1. Press if a fruit word or a good word (requiring the subject to withhold a response to bug words or to bad words).

2. Press if a bug word or a bad word (requiring the subject to withhold a response to fruit words or to good words).

In the remaining two block types, instructions required subjects to respond only to a combination of words that was incongruent in terms of prior associations:

3. Press if a fruit word or a bad word (requiring the subject to withhold a response to bug words or to good words).

4. Press if a bug word or a good word (requiring the subject to withhold a response to fruit words or to bad words).

Participants completed 2 blocks of each experimental condition, yielding a total of eight blocks.

\section{ERP recording and data analyses}

The EEG was recorded from the scalp with reference to the activity on the left mastoid using 29 tin electrodes mounted in an elastic cap and positioned at standard locations. Vertical eye movements were monitored with an electrode positioned below the right eye. Horizontal eye movements were monitored by using two electrodes placed on the left and right external canthus. All electrode impedances were kept below $5 \mathrm{k} \Omega$. The electrophysiological signals were filtered with a bandpass of $0.01-70 \mathrm{~Hz}$ and digitized at a rate of $250 \mathrm{~Hz}$. Trials with excessive eye movement artefacts $(14.7 \%)$, detected by recording of the vertical and horizontal electrooculogram, were excluded from further analyses (maximal allowed voltage step/sampling point $=50 \mu \mathrm{V}$; maximal allowed absolute difference of two values in the segment $=100 \mu \mathrm{V}$ ). Correct trials were averaged separately for congruent and incongruent conditions for epochs of $1024 \mathrm{~ms}$ including a 100 $\mathrm{ms}$ prestimulus baseline. Mean amplitudes were computed for different time windows, which were subjected to analyses of variance (ANOVA) as described in the Results section. All ERP 
waveforms in the figures were digitally filtered using a low-pass filter with an $8-\mathrm{Hz}$ half amplitude cutoff.

\section{Results}

\section{Behavioral data}

As described above, subjects were instructed to respond to certain stimuli and to withhold responses to others. For half of the blocks, instructions required subjects only to respond to a combination of words that was congruent (press if bug word or bad word, press if fruit word or good word), while in the remaining blocks, instructions required subjects only to respond to a combination of words that was incongruent (press if bug word or good word, press if fruit word or bad word). Participants made only very few errors $(4.5 \%$ overall, $3.9 \%$ across trials in congruent blocks, $5 \%$ across trials in incongruent blocks).
Table 2

Results for N200 effect "fruit/bug" words

\begin{tabular}{lccc}
\hline & Congruency & Cong.*hemisphere & Cong.* ${ }^{*}$ site \\
\hline $200-250 \mathrm{~ms}$ & 0.05 & $16.5^{*}$ & $5.7+$ \\
$250-300 \mathrm{~ms}$ & $8.6+$ & $11.8^{*}$ & 1.1 \\
$300-350 \mathrm{~ms}$ & $18.5^{*}$ & $6.0+$ & 0.9 \\
$350-400 \mathrm{~ms}$ & $5.8+$ & 2.4 & 0.4 \\
$400-450 \mathrm{~ms}$ & 0.2 & 4.8 & 2.1 \\
$450-500 \mathrm{~ms}$ & 4.7 & $13.9^{*}$ & $15.9^{*}$ \\
\hline
\end{tabular}

The analyses of the response latencies on Go trials showed a main effect of type of word $(F(3,10)=30,02, P<0.01)$. Post hoc comparisons revealed that subjects responded faster to category words $(624 \mathrm{~ms}, \mathrm{SEM}=36)$ than to evaluative words $(716 \mathrm{~ms}, \mathrm{SEM}=$ 32; $T(10)=4,3, P<0.01)$. As expected, subjects also responded faster to trials in congruent blocks $(637 \mathrm{~ms}, \mathrm{SEM}=24)$ than to trials in incongruent blocks $(700 \mathrm{~ms}, \mathrm{SEM}=27 ; F(1,10)=17,63, P<$

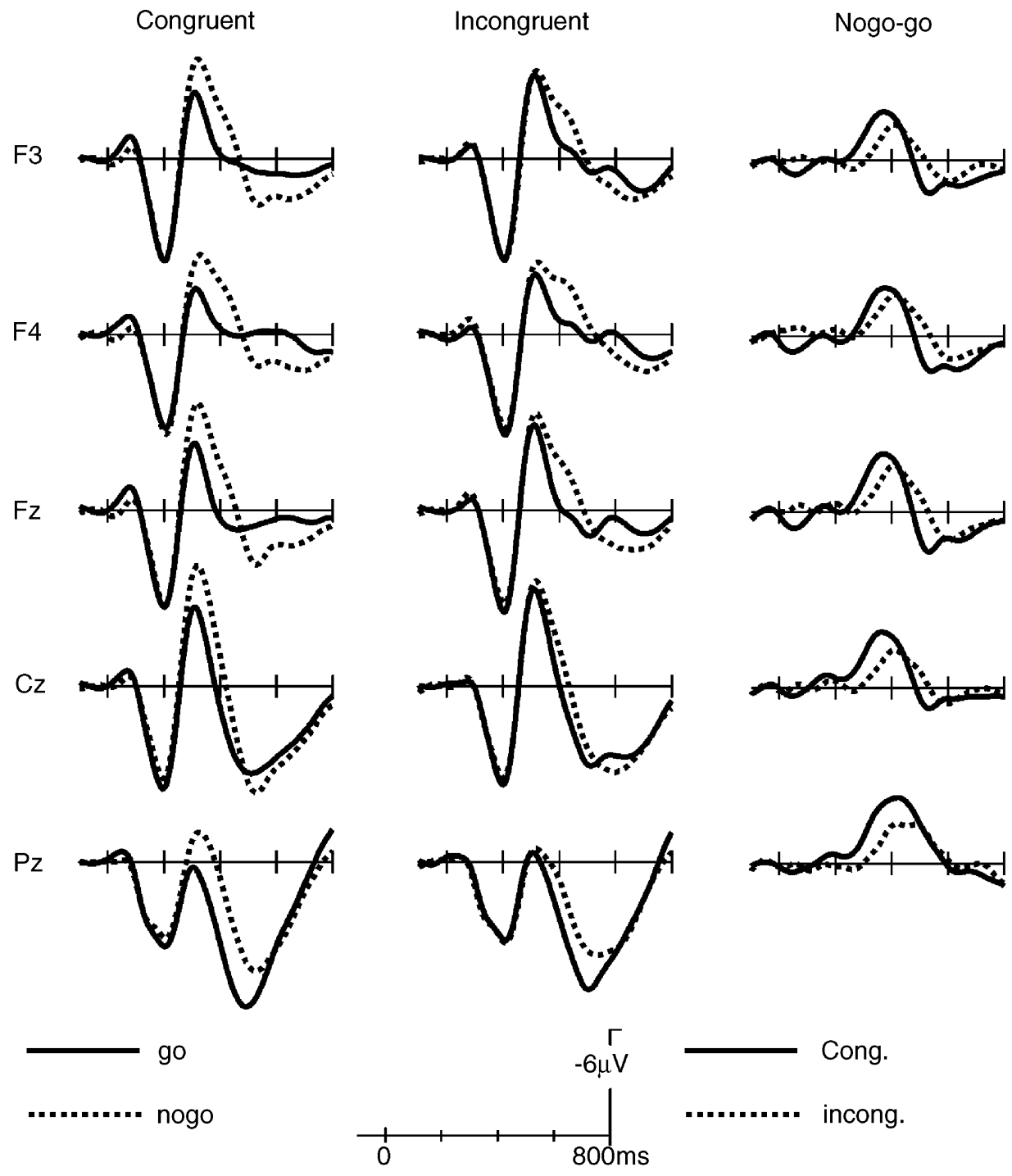

Fig. 1. Grand average ERPs (collapsed over fruit and bugs categories) for congruent (left column) and incongruent (middle column) trials for selected electrodes. Clearly, the NoGo trials are associated with a greater negativity ("N200") in both classes of stimuli that has a frontal distribution (see scalp map). The difference waves reveal that this NoGo-related activity has a later onset in the incongruent trials. 


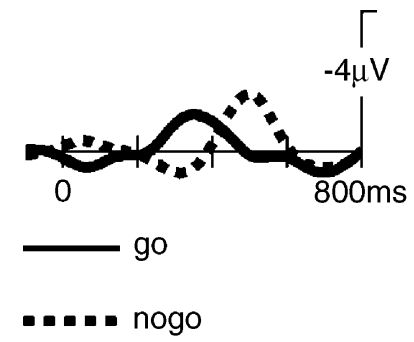

Fig. 2. Difference waves (incongruent trials minus congruent trials) for the midfrontal site. These illustrate different effects of congruency for Go and NoGo trials: While Go trials show negativity with an onset of about 250 $\mathrm{ms}$, a small positivity is seen in this latency range for NoGo trials, which is followed by a larger negativity. This biphasic effect in the NoGo trials is consistent with an initial tendency to respond in the direction of the stereotypical association (suggesting a Go response), which has to be overcome.

$0.01)$. There was no significant interaction between congruency and the type of word $(P>0.1)$.

\section{ERPs}

The grand average ERPs to fruit/bug words are shown for selected electrode sites in Fig. 1. These are characterized by a small initial negativity followed by a sharp positivity at about $200 \mathrm{~ms}$ (P200) followed by a further negative deflection peaking at about $320 \mathrm{~ms}$. For the congruent blocks, Go and NoGo trials were associated with virtually identical ERPs up to $230 \mathrm{~ms}$. From then onwards, NoGo trials showed an increased negativity, which can be identified as the N200 effect and shows a typical frontal distribution (see scalp maps, Fig. 1). In the incongruent blocks, a similar picture emerged. In this case, the point of divergence between Go and NoGo trials is somewhat later. The presence of an N200 NoGo effect was confirmed entering the mean amplitude (300-500 ms, F3/4, C3/4, Fc1/2) of Go and NoGo trials into an analysis of variance. A main effect of $\mathrm{Go} / \mathrm{NoGo}$ was obtained for trials in both congruent $(F(1,10)=48.4, P<0.001)$ and incongruent $(F(1,10)=10.5, P<0.01)$ blocks. The differential activity for NoGo versus Go trials is isolated by the respective difference waves. While visual inspection suggests the onset of the $\mathrm{N} 200$ to be about $230 \mathrm{~ms}$ in trials in the congruent blocks, it is about $50 \mathrm{~ms}$ later in trials in the incongruent blocks. This latency difference was assessed in several different ways. First, computing the mean amplitude of the NoGo-Go difference waves in $50 \mathrm{~ms}$ time windows between 100 and $500 \mathrm{~ms}$ (electrode sites F3/4, Fc1/2, C3/4) a main effect of congruency was found between 250 and $400 \mathrm{~ms}$ (see Table 2).

This onset difference was corroborated by two additional analyses: First, onset latency was estimated by determining the time-point by which the area under the curve (time window $100-500 \mathrm{~ms}$ ) had reached $25 \%$. This measure was used to assess the onset of ERP components using a jackknife-based method. In a first pass analysis, the total area under a component in a specified time window is computed (in this case, the negative area under the N200 component). In a second pass, it is calculated at what sampling point a prespecified fraction of the total area is reached (in this case $25 \%$ ). This fractional area latency measure
Congruent
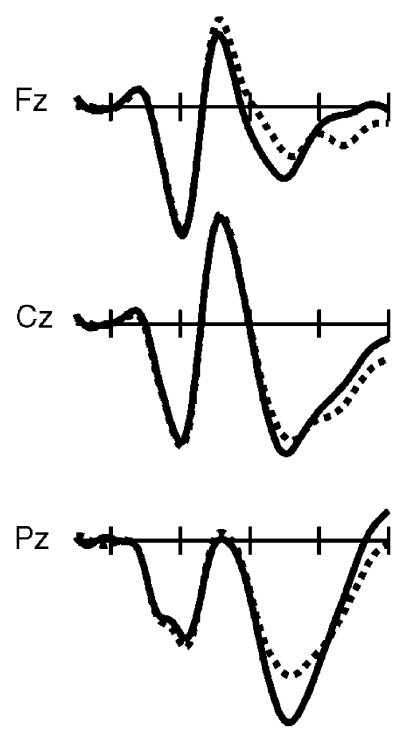

go

nogo

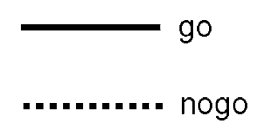

Incongruent
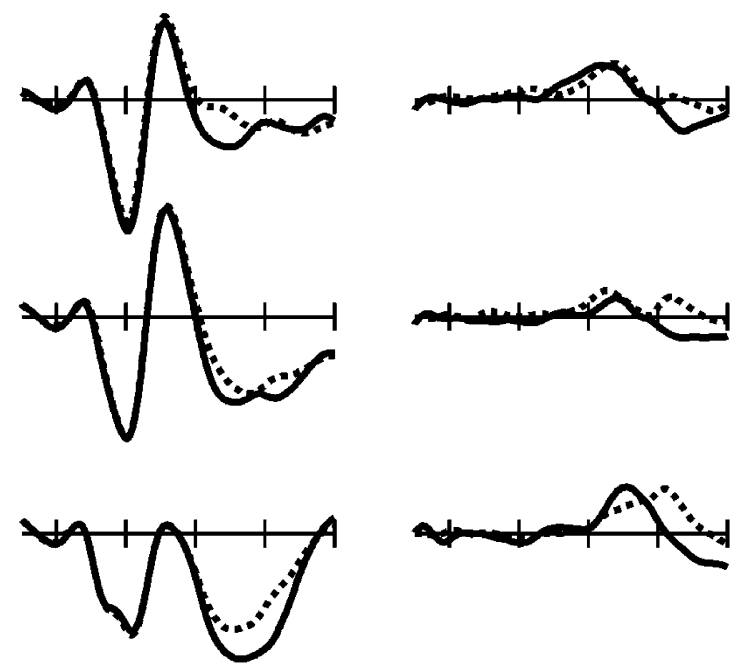

nogo-go

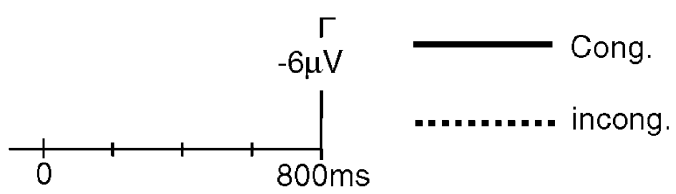

Fig. 3. Grand average ERPs for "good/bad" words. While an N200 component is observed for the NoGo trials for congruent (left column) and incongruent (middle column) conditions, the difference waves (right column) show that this NoGo-related activity has similar latency characteristic for Go and NoGo trials. 
was used in combination with jackknifing to make it less susceptible to individual subject noise than the more standard peak latency measure (Luck, 1998; Miller et al., 1998). This yielded an onset latency of $328 \mathrm{~ms}$ for trials in congruent blocks versus $364 \mathrm{~ms}$ for trials in incongruent blocks $\left(T_{\mathrm{j}}(10)=2.13, P<\right.$ $0.05)$.

Secondly, this latency difference was further assessed by computing sequential $t$ tests on the mean amplitude (midfrontal site) in a $40 \mathrm{~ms}$ running time window against zero (step-size $8 \mathrm{~ms}$ ) (Rodriguez-Fornells et al., 2005; Schmitt et al., 2001). The onset was defined as the first window where the mean amplitude was significantly below zero $(P<0.05)$. The N200 effect had an earlier onset in trials in congruent blocks (in the time window between 232 and $272 \mathrm{~ms}$ ) as compared to trials in incongruent blocks (between 288 and $328 \mathrm{~ms}$ ). The two conditions significantly differ in the time windows starting between 248 and $368 \mathrm{~ms}$.

The effects of congruency were isolated by computing the incongruent-congruent difference waves separately for Go and NoGo trials (Fig. 2). For the Go trials, the onset of the congruency effect was about $250 \mathrm{~ms}$ and thus coincided with the onset of the N200 NoGo effect. In the NoGo trials, a different picture emerged: here, a small positivity was observed with an onset of $250 \mathrm{~ms}$ followed by a negative deflection peaking at about $500 \mathrm{~ms}$. Mean amplitude in two time windows was calculated and a 2 (Time window: 150-300 ms, 350-500 ms) $\times 2$ (Trial type: Go, NoGo) $\times 3$ (Electrode: frontal, frontocentral, central) $\times 2$ (hemisphere) analysis of variance revealed an effect of Time window $(F(1,10)=7.77, P<0.02)$ reflecting the increased overall negativity in the later time window. Moreover, Go trials were more negative than NoGo trials in the early time window $(-0.82 \mu \mathrm{V}$ [SD 0.63] versus $0.32 \mu \mathrm{V}$ [SD 0.94]), and more positive in the later time window $(-0.54 \mu \mathrm{V}$ [SD 0.81] versus $-0.28 \mu \mathrm{V}$ [SD 1.18], interaction time window by trial type, $F(1,10)=26.7, P<0.001)$, indicating that in the NoGo trials an initial tendency to respond in the direction of the evaluative association (suggesting a Go response) had to be overcome.

We also looked at the NoGo-effects for the "good/bad" words (Fig. 3) and carried out similar analyses as for the "fruit/bug" words (see above). While a small N200 was present for trials in both congruent $(F(1,10)=6.20, P<0.05)$ and incongruent $(F(1,10)=33.5, P<0.001)$ blocks, visual inspection of the difference waves suggested no latency or amplitude differences. In fact, computing the mean amplitude of the difference waves in 50 $\mathrm{ms}$ steps revealed neither main effects of congruency nor interactions of congruency with either hemisphere or electrode site. Additionally, neither the running $t$ test, nor the fractional area latency analyses yielded a congruency effect for the onset of this small N200 effect.

Finally, a pair of correlation analyses were performed to further elucidate the specific link of the behavioral implicit association effect and the N200 onset effect. If it is true that the implicit associations drive the N200 differences, then individual differences in the strength of association should predict this difference. For people without an association, there should be no difference. For people with the strongest implicit associations, the difference should be the largest. Individual N200 onset latency (Fractional Area Latency $20 \%$, time window $200-700 \mathrm{~ms}$, bandpass 2-6 Hz) was correlated with the GNAT effect for "fruit/bug" words, $r(9)=$ $0.64, P<0.05$, but it was not correlated with the GNAT effect for "good/bad" words, $r(9)=0.16, P>0.5$.

\section{Discussion}

We investigated the electrophysiological components of response inhibition in a GNAT task, using a classic fruit/bugs design that has previously yielded solid behavioral results (Nosek and Banaji, 2001). As mentioned earlier, the GNAT is a tool designed to measure an individual's implicit attitudes towards certain objects or categories of people. Amongst other issues, the IAT and the GNAT have thus far been used to successfully measure implicit associations towards weight identity in overweight and underweight males and females (Grover et al., 2002), attitudes towards ethnic categories (Greenwald et al., 1998), gender differences in arts and sciences (Nosek et al., 2002), and age differences in implicit social cognitions (Hummert et al., 2002). Thus far, little is known about the neural processes involved in such implicit cognition towards category targets. In terms of behavioral results, we replicated previous findings (Nosek and Banaji, 2001), in that subjects responded faster in trials where the instruction pairing was congruent ("Press if a bug word or a bad word"/"Press if a fruit word or a good word") than in trials where the instruction pairing was incongruent ("Press if a bug word or a good word"/"Press if a fruit word or a bad word"), suggesting that our subjects held a positive automatic attitude towards fruit and a negative automatic attitude towards bugs.

The results of the present experiment are also consistent with previous work on the N200 - "NoGo" - component (Schmitt et al., 2000, 2001; Rodriguez-Fornells et al., 2002, 2005) and with our hypotheses. As expected, we found NoGo trials to be associated with greater negativity as compared to Go trials from approximately $250 \mathrm{~ms}$ onwards. We isolated this N200 effect by computing NoGo-Go difference waves for congruent and incongruent trials separately (see Fig. 1). Crucially, we found delayed negativity in incongruent as compared to congruent trials. In fact, the N200 onset latency was delayed by about $50 \mathrm{~ms}$ in the incongruent trials relative to the congruent trials. While these ERP data are consistent with the RT effects seen for Go trials, it has to kept in mind that the latter show differences between incongruent and congruent trials as late as $600-700 \mathrm{~ms}$, while the electrophysiological data suggest that the implicit associations must have been activated much earlier, i.e., at the point of divergence between the N200 effects in congruent and incongruent trials. Note that this value, in the present study approximately $250 \mathrm{~ms}$, can be taken as the upper limit of the time at which this associative information becomes available (see Rodriguez-Fornells et al., 2002, 2005; Schmitt et al., 2000, 2001, for a similar logic in tacit picture naming experiments). The scalp topography of the N200 in the present experiment (Fig. 1) is consistent with previous experiments and shows a frontal distribution.

In order to look at these congruency effects in more detail, we further calculated difference waves for trials in incongruent blocks minus trials in congruent blocks for both Go and NoGo conditions (see Fig. 3). These difference waves reveal a biphasic nature of the congruency effect; there was an early negativity on Go trials, and an early positivity followed by a larger negativity on NoGo trials. This is consistent with the notion that the N200 reflects the amount of information in support of suppressing (NoGo) rather than initiating the response (Go), as outlined earlier. For NoGo trials, it is likely that the automatic associations already in place interfered with the task instructions to withhold a response, resulting in a small early positivity and a delayed subsequent negativity. For example, when instructed 'press if a fruit word or a bad word', an 
insect word activates negative associations that suggest that the button needs to be pressed. Similarly, the early negativity found for Go trials suggests an early partial inhibition of the response. So, when instructed 'press if a fruit word or a bad word', a fruit word activates positive associations that suggest that a response needs to be withheld. These results are important as they further elucidate the time course of this type of information processing and show how attitudes, as measured by implicit associations, can affect early stages of processing.

In summary, we obtained two congruency effects in the ERP data. We found a latency effect in NoGo-specific activity for trials in Incongruent versus Congruent blocks and two different phases in Incongruency-specific activity for NoGo versus Go trials. Importantly, both congruency effects on the N200 were confined to the taxonomic target categories fruit and bugs and did not occur for the ERPs of the good and bad words (Fig. 3). This suggests that it is not the pairing of incongruent words in the instruction per se that drives the N200 effect (if this was the case, then there would also be latency effects for the good/bad words, and there are not), but rather the activation of positive or negative prior associations that occurs as a consequence of viewing the fruit or bug words (see Hebb, 1949). The good and bad words are not likely to be associated with the categories fruit or bugs and are therefore unlikely to produce early conflicting information in the same way that fruit and bug words do with the evaluations good and bad. Of course, bad words are still evaluated as negative and good words are still evaluated as positive. Nothing changes with respect to the evaluation of the word "revolting", it will still activate its negative associations, however, the word "revolting" will not activate "spider", "bug" or some other insect word (at least not to a similar extent as "insect" and "fruit" words activate their evaluative associations "bad" and "good").

The later RT effects tell a different story. Here, we see congruency effects for both target category and evaluative attribute words. RT effects occur considerably later than the ERP components of interest (approximately 600-700 ms) and therefore may reflect later, more strategy-based processing. In an investigation of the underlying mechanisms of the implicit association task, Brendl et al. (2001) have convincingly shown that subjects can shift their response criterion when completing the IAT. They suggest that response patterns in the IAT may be driven by several factors, such as perceived difficulty within blocks (resulting from response competition integral in both the IAT and the GNAT). It is therefore possible that the congruency effect we find in RTs for all types of words (i.e., for good and bad words as well as fruit and bugs words) in the GNAT may simply reflect a more conscious strategy on the subjects' part to delay the response in the face of incongruent instructions. Although it is possible that a similar mechanism could account for the early N200 onset effect, the absence of a congruency effect for the word trials, together with the biphasic nature of the congruency effect for fruit and bugs, makes it unlikely that the delay in N200 onset simply reflects a strategical slowing in incongruent blocks.

To recap, congruency effects for the N200 were confined to the taxonomic target categories fruit and bugs and did not occur for the ERPs of the good and bad words. However, we found congruency effects for both target category and evaluative attribute words in the later RT data. It is possible that this difference between ERP and behavioral data points to two different sources of the GNAT effect for fruits and bugs. The N200 modulation appears to index an early effect of interference through prior associations. Our explanation that implicit associations drive the early differentiation in $\mathrm{N} 200$ onset is further supported by correlational analyses. These show that individual differences in the strength of association for fruit and bug words, but not for good and bad words, predict the individual N200 onset differences. As these effects occur so early, they lend further support to the idea that attitude information can be automatically activated and can occur out of awareness (e.g., Fazio, 2001; Greenwald and Banaji, 1995; Greenwald and Farnham, 2000; Greenwald et al., 1998; Nosek and Banaji, 2001). The RT differences, on the other hand, appear to also reflect a strategy to withhold the response in incongruent blocks that is not reflected in this early ERP component. Other possible influences on IAT (and therefore GNAT) effects, as measured by response times, include subjects' cognitive ability to suppress incongruent information (McFarland and Crouch, 2002), stimulus - response compatibility (De Houwer, 2001), and task-switching costs (Back et al., 2005; Klauer and Mierke, 2005). Again, such factors might have influenced the RT data, but it is unlikely that they influence the N200 onset effect reported here (for similar reasons as outlined above for the response criterion shift). However, future work could address this issue more directly.

Future studies could also investigate automatic/controlled aspects of this type of information processing in more detail and, with reference to different target groups, including social groups (for example implicit attitudes towards elderly versus young people). Recently, researchers have tracked the time course of different aspects of social evaluation. This research suggests that very basic categorizations (such as race) may take place as early as $120 \mathrm{~ms}$ (see Ito and Urland, 2003, 2005). Ito et al. (2004) have shown that, when viewing faces of racial in- and out-group members, in-group members can be differentiated from out-group members as early as $250 \mathrm{~ms}$. These studies address issues of spontaneous social categorization. An ERP study employing the GNAT would add to this work by elucidating both the strength of association held between the target category and the poles of and attribute dimension and the time-point at which such associations become available as reflected in brain activity.

Finally, note that neither the GNAT, nor its dual response predecessor the IAT, was designed to measure beliefs per se, but rather the strength of an association between a category or concept and an evaluative dimension (see Greenwald et al., 1998). While such associations may well constitute part of beliefs, they do not necessarily measure the nature or the direction of the association or the complex qualified associations between concepts that also contribute to beliefs (see de Jong et al., 2001). It makes sense that the impact of associative associations (and any mechanisms involved in subsequent behavioral control) will vary as a result of the type of stimuli used in the present paradigm, for example how emotionally salient or personally relevant the target category is will in turn affect how it is processed (see Veit et al., 2002). We used the classic fruit/bugs design, which has provided robust behavioral results, as a starting point to investigate how early associative information can become available. As suggested by our post hoc correlational analyses, it is likely that the strength of association between the target category and the evaluative dimension can exacerbate or moderate these early effects. Future work could also address whether there are individual and group differences with regard to the impact of such information processing. 


\section{Conclusion}

We show that attitudes held about fruit and bugs appear to affect very early stages of processing, with $250 \mathrm{~ms}$ representing the upper time limit at which this type of information becomes available. Congruency effects in the N200 component appear to be driven by early interference from prior associations, whereas effects in reaction latency may also reflect later, more controlled, strategic processing. This study shows that ERPs can be used to provide more detailed information about the time course of information processing in implicit Go/NoGo association tasks.

\section{Acknowledgments}

We thank Dana Heinze and Caterina Rohrbach for their help with data collection. This research was supported by the Deutsche Forschungsgemeinschaft and by the BMBF (contract 01GO0202).

\section{Appendix A. List of stimuli used in the GNAT (translated from German)}

\begin{tabular}{|c|c|c|c|}
\hline Fruit words & Bug words & Positive words & Negative words \\
\hline Melon & Ants & Heartwarming & Revolting \\
\hline Banana & Wasp & Great & Anxious \\
\hline Plum & Flies & Joy & Nasty \\
\hline Cherry & Cricket & Cute & Heartless \\
\hline Mango & Grasshopper & Holiday & Hell \\
\hline Fruit & Flea & Fabulous & Snobby \\
\hline Orange & Woodworm & Excitement & Funeral \\
\hline Grape & Hornet & Flowers & Hate \\
\hline Raspberry & Beetle & Happiness & Dislike \\
\hline Lemon & Grub & Fun-Loving & Torture \\
\hline Mandarin & Louse & Jackpot & Dirty \\
\hline Date & Dragonfly & Paradise & Extermination \\
\hline Quince & Spider & Delicious & Selfish \\
\hline Nectarine & Mosquito & Laughing & Yucky \\
\hline Gooseberry & Moth & Prize & Arrogant \\
\hline Passion Fruit & Earwig & Loving & Disaster \\
\hline Strawberry & Caterpillar & Hospitable & Abattoir \\
\hline Pear & Roach & Kiss & Sickening \\
\hline Pineapple & Maggot & Sunshine & Miserable \\
\hline Blueberry & Tarantula & Hug & Cavities \\
\hline Pomegranate & Centipede & Silk & Bombs \\
\hline Apricot & Bedbug & Fantastic & Conceited \\
\hline Grapefruit & Bee & Dancing & Homicide \\
\hline Peach & Termite & Luxurious & Mortal Agony \\
\hline Apple & Worm & Adventuresome & Despicableness \\
\hline
\end{tabular}

\section{References}

Bar, M., 2003. A cortical mechanism for triggering top-down facilitation in visual object recognition. J. Cogn. Neurosci. 15, 600-609.

Bargh, J.A., Chen, M., Burrows, L., 1996. Automaticity of social behaviour: direct effects of trait construct and stereotype activation on action. J. Pers. Soc. Psychol. 71, 230-244.

Baayen, R.H., Piepenbrock, R., van Rijn, H., 1993. The CELEX Lexical Database. Linguistic Data Consortium, University of Pennsylvania, Philadelphia.

Back, M.D., Schmukle, S.C., Egloff, B., 2005. Measuring task-switching ability in the Implicit Association Test. Exp. Psychol. 52, 167-179.
Brendl, M., Markman, A.B., Messner, C., 2001. How do indirect measures of evaluation work? Evaluating the inference of prejudice in the Implicit Association Test. J. Pers. Soc. Psychol. 81, 760-773.

Carretié, L., Hinojosa, J.A., Mercado, F., Tapia, M., 2005. Cortical responses to subjectively unconscious danger. NeuroImage 24, 615-623.

Casey, B.J., Trainor, R.J., Orendi, J.L., Schubert, A.B., Nystrom, L.E., Cohen, J.D, Noll, D.C., Giedd, J., Castellanos, X., Haxby, J., Forman, S.D., Dahl, R.E., Rapoport, J.L., 1997. A pediatric functional MRI study of prefrontal activation during performance of a Go-No-Go task. J. Cogn. Neurosci. 9, 835-847.

Chen, M., Bargh, J.A., 1999. Consequences of automatic evaluation: immediate behavioral predispositions to approach or avoid the stimulus. Pers. Soc. Psychol. Bull. 25, 215-224.

De Houwer, J., 2001. A structural and process analysis of the Implicit Association Test. J. Exp. Soc. Psychol. 37, 443-451.

Duckworth, K.L., Bargh, J.A., Garcia, M., Chaiken, S., 2002. The automatic evaluation of novel stimuli. Psychol. Sci. 13, 513-519.

Fazio, R.H., 2001. On the automatic activation of associated evaluations: an overview. Cognition and Emotion 15, 115-141.

Fazio, R.H., Olson, M.A., 2003. Implicit measures in social cognition research: their meaning and use. Annu. Rev. Psychol. 54, 297-327.

Fazio, R.H., Sanbonmatsu, D.M., Powell, M.C., Kardes, F.R., 1986. On the automatic activation of attitudes. J. Pers. Soc. Psychol. 50, 229-238.

Fazio, R.H., Jackson, J.R., Dunton, B.C., Williams, C.J., 1995. Variability in automatic activation as an unobtrusive measure of racial attitudes: a bona fida pipeline? J. Pers. Soc. Psychol. 69, 1013-1027.

Fuster, J.M., 1989. The prefrontal Cortex: Anatomy, Physiology, and Neuropsychology of the Frontal Lobe, 2nd edition Raven Press, New York

Garavan, H., Ross, T.J., Stein, E.A., 1999. Right hemispheric dominance of inhibitory control: an event-related functional MRI study. P. Natl. Acad. Sci. U. S. A. 96, 8301-8306.

Gemba, H., Sasaki, K., 1989. Potential related to no-go reaction pf go/no-go hand movement task with color discrimination in human. Neurosci. Lett. 101, 263-268.

Greenwald, A.G., Banaji, M.R., 1995. Implicit social cognition: attitudes, self-esteem, and stereotypes. Psychol. Rev. 102, 4-27.

Greenwald, A.G., Farnham, S.D., 2000. Using the implicit association test to measure self-esteem and self-concept. J. Pers. Soc. Psychol. 79, $1022-1038$.

Greenwald, A.G., McGhee, D.E., Schwartz, J.L.K., 1998. Measuring individual differences in implicit cognition: the implicit association test. J. Pers. Soc. Psychol. 74, 1464-1480.

Greenwald, A.G., Banaji, M.R., Rudman, L.A., Farnham, S.D., Nosek, B.A., Mellott, D.S., 2002. A unified theory of implicit attitudes, stereotypes, self-esteem, and self-concept. Psychol. Rev. $109,3-25$.

Grover, V.P., Keel, P.K., Mitchell, J.P., 2002. Gender differences in implicit weight identity. Int. J. Eat. Disord. 34, 125-135.

Hebb, D.O., 1949. Organization of Behavior. Wiley, New York.

Holmes, A., Vuilleumier, P., Eimer, M., 2003. The processing of emotional facial expression is gated by spatial attention: evidence from event related brain potentials. Cognit. Brain Res. 16, 174-184.

Hummert, M.L., Garstka, T.A., O’Brien, L.T., Greenwald, A.G., Mellott, D.S., 2002. Using the implicit association test to measure age differences in implicit social cognitions. Psychol. Aging 17, $482-495$.

Ito, T.A., Urland, G.R., 2003. Race and gender on the brain: electrocortical measures of attention to the race and gender of multiply categorizable individuals. J. Pers. Soc. Psychol. 85, 616-626.

Ito, T.A., Urland, G.R., 2005. The influence of processing objectives on the perception of faces: an ERP study of race and gender perception. Cogn. Affect. Behav. Neurosci. 5, 21-36.

Ito, T.A., Thompson, E., Cacioppo, J.T., 2004. Tracking the timecourse of social perception: the effects of racial cues on event-related brain potentials. Pers. Soc. Psychol. Bull. 30, 1267-1280. 
Jansma, B.M., Rodriguez-Fornells, A., Möller, J., Münte, T.F., 2004. Electrophysiological studies of speech production. Klinische Neurophysiologie 35, 1-8.

de Jong, P., Pasman, W., Kindt, M., van den Hout, M.A., 2001. A reaction time paradigm to assess (implicit) complaint-specific dysfunctional beliefs. Behav. Res. Ther. 39, 101-113.

Kawakami, K., Dovisio, J.F., Dijksterhuis, A., 2003. Effect of social category priming on personal attitudes. Psychol. Sci. 14, 315-319.

Kawasaki, H., Adolphs, R., Kaufman, O., Damasio, H., Damasio, A.R., Granner, M., Bakken, H., Hori, T., Howard, M.A., 2001. Single neuron responses to emotional visual stimuli recorded in human ventral prefrontal cortex. Nat. Neurosci. 4, 15-16.

Klauer, K.C., Mierke, J., 2005. Task-set inertia, attitude accessibility, and compatibility-order effects: new evidence for a task-set switching account of the IAT effect. Pers. Soc. Psychol. Bull. 31, $208-217$.

Konishi, S., Nakajima, K., Uchida, I., Kikyo, H., Kameyama, M., Miyashita, Y., 1999. Common inhibitory mechanism in human inferior prefrontal cortex revealed by event-related functional MRI. Brain 122, $191-981$.

Kok, A., 1986. Effects of degradation of visual stimulation on components of the event-related potential (ERP) in go/nogo reaction task. Biol. Psychol. 23, 21-38.

Lakin, J.L., Chartrand, T.L., 2003. Using nonconscious behavioural mimicry to create affiliation and rapport. Psychol. Sci. 14, 334-339.

LeDoux, J., 1998. Fear and the brain: where have we been, and where are we going? Biol. Psychiatry 44, 1229-1238.

Luck, S.J., 1998. Sources of dual-task interference: evidence from human electrophysiology. Psychol. Sci. 9, 223-227.

Luria, A.R., 1973. The Working Brain. Basic Books, New York.

Menon, V., Adleman, N.E., White, C.D., Glover, G.H., Reiss, A.C., 2001. Error-related brain activation during a Go/NoGo response inhibition task. Hum. Brain Mapp. 12, 131-143.

McFarland, S.G., Crouch, Z., 2002. A cognitive skill confound on the Implicit Association Test. Social Cognition 20, 483-510.

Miller, J., Patterson, T., Ulrich, W., 1998. Jackknife-based method for measuring LRP onset latency differences. Psychophysiology 35, $99-115$.

Münte, T.F., Urbach, T.P., Düzel, E., Kutas, M., 2000. Event-related brain potentials in the study of human cognition and neuropsychology. In: Boller, F., Grafman, J., Rizzolatti, G. (Eds.), Handbook of Neuropsychology, 2nd ed., vol. 1. Elsevier, New York, pp. $139-235$.

Murphy, S.T., Zajonc, R.B., 1993. Affect, cognition, and awareness: affective priming with optimal and suboptimal stimulus exposures. J. Pers. Soc. Psychol. 64, 723-739.

Nosek, B.A., Banaji, M.R., 2001. The Go/NoGo association task. Social Cognition 19, 625-664.

Nosek, B.A., Banaji, M.R., Greenwald, A.G., 2002. Math = Male, $\mathrm{Me}=$ Female, Therefore Math $\neq$ Me. J. Pers. Soc. Psychol. 83, 44-59.

Osgood, C.E., 1953. Method and Theory in Experimental Psychology. Oxford University Press, New York.
Pfefferbaum, A., Ford, J.M., Weller, B.J., Kopell, B.S., 1985. ERPs to response production and inhibition. Electroencephalogr. Clin. Neurophysiol. $60,423-434$.

Rahman, R.A., van Turennout, M., Levelt, W.J., 2003. Phonological encoding is not contingent on semantic feature retrieval: an electrophysiological study on object naming. J. Exp. Psychol. Learn. Mem. Cogn. 29, 850-860.

Rodriguez-Fornells, A., Münte, T.F., Clahsen, H., 2002. Morphological priming in Spanish verb forms: an ERP repetition priming study. J. Cogn. Neurosci. 14, 443-454.

Rodriguez-Fornells, A., van der Lugt, A., Rotte, M., Britti, B., Heinze, H.J., Münte, T.F., 2005. Second language interferes with word production in fluent bilinguals: brain potential and functional imaging evidence. J. Cogn. Neurosci. 17, 422-433.

Sasaki, K., Gemba, H., 1993. Action of the cerebello-thalamo-cortical projection upon visually initiated reaction-time hand movements in the monkey. Stereotact. Funct. Neurosurg. 60, 104-120.

Sasaki, K., Gemba, H., Tsujimoto, T., 1989. Suppression of visually initiated hand movement by stimulation of the prefrontal cortex in the monkey. Brain Res. 495, 100-107.

Sasaki, K., Gemba, H., Nambu, A., Matsuzaki, R., 1993. No-go activity in the frontal association cortex of human subjects. Neurosci. Res. 18, 249-252.

Schmitt, B.M., Münte, T.F., Kutas, M., 2000. Electrophysiological estimates of the time course of semantic and phonological encoding during implicit picture naming. Psychophysiology 37, 473-484.

Schmitt, B.M., Schiltz, K., Zaake, W., Kutas, M., Münte, T.F., 2001. An electrophysiological analysis of the time course of conceptual and syntactic encoding during tacit picture naming. J. Cogn. Neurosci. 13, 510-522.

Schupp, H.T., Ohman, A., Junghofer, M., Weike, A.I., Stockberger, J., Hamm, A.O., 2004. The facilitated processing of threatening faces: an ERP analysis. Emotion 4, 189-200.

Simson, R., Vaughan, H.G., Ritter, W., 1977. The scalp topography of potentials in auditory and visual Go/NoGo tasks. Electroencephalogr. Clin. Neurophysiol. 43, 864-875.

Stapel, D.A., Blanton, H., 2004. From seeing to being: subliminal social comparisons affect implicit and explicit evaluations. J. Pers. Soc. Psychol. 87, 468-481.

Thorpe, S., Fize, D., Marlot, C., 1996. Speed of processing in the human visual system. Nature 381, 520-522.

Veit, R., Flor, H., Erb, M., Hermann, C., Lotzse, M., Grodd, W., Birbaumer, N., 2002. Brain circuits involved in emotional learning in antisocial behavior and social phobia in humans. Neurosci. Lett. 328, $233-236$.

Vuilleumier, P., 2002. Facial expression and selective attention. Curr. Opin. Psychiatr. 15, 291-300.

Zajonc, R.B., 1980. Feeling and thinking: preferences need no inferences. American Psychologist 35, 151-175.

Zajonc, R.B., 1984. On the primacy of affect. American Psychologist 37, 117-123.

Zajonc, R.B., 2001. Mere exposure: a gateway to the subliminal. Current Directions in Psychological Science 10, 224-228. 